\section{Reply to the "Discussion of Determination of Activities of Niobium in Cu-Nb Melts Containing Dilute $\mathrm{Nb}^{\prime \prime}$}

\section{DAYA WANG, BAIJUN YAN, and DU SICHEN}

DOI: $10.1007 / \mathrm{s} 11663-015-0406-y$

(C) The Minerals, Metals \& Materials Society and ASM International 2015

Prof. Jacob wrote a discussion on the "Determination of Activities of Niobium in $\mathrm{Cu}-\mathrm{Nb}$ Melts Containing Dilute Nb". The authors' reply to the discussion is given below.

(1) In the first place, we are thankful to Prof. Jacob for pointing out the mistake in our communication regarding the standard state for $\mathrm{Nb}$. The listed values calculated using the equations from Hämäläinen et al. ${ }^{[2]}$ and Kaufman ${ }^{[3]}$ (Eqs. [3] and [4] in the communication paper) refer pure solid $\mathrm{Nb}$ as standard state. The authors have compared with their own data using pure liquid as standard state. It is a serious mistake. A new Table II is presented below to provide the readers correct information.

(2) Prof. Jacob thought that a stagnant gas column would exist over liquid $\mathrm{Cu}$ in the alumina crucible, and the concentration of $\mathrm{CO}_{2}$ would have been higher and that of $\mathrm{CO}$ lower in the gas boundary layer above liquid copper than the inlet gas composition.

The authors would not agree with his argument. Using gas mixture to control oxygen potential has been used successfully by so many researchers. This is wellestablished technique for thermodynamic study. If the reaction time is long enough and the gas flow rate is not low, the oxygen potential of the system will be the same as the gas phase. In the experiments of Wang et al. ${ }^{[1]}$, the

DAYA WANG, Doctoral Student, and BAIJUN YAN, Professor, are with the State Key Laboratory of Advanced Metallurgy, School of Metallurgical and Ecological Engineering, University of Science and Technology Beijing, Beijing 100083, P.R. China. DU SICHEN, Professor, is with the Department of Materials Science and Engineering, Royal Institute of Technology, 10044, Stockholm, Sweden. Contact e-mail: sichen@kth.se

Manuscript submitted May 27, 2015

Article published online July 9, 2015 equilibrium times are 24 hours at $T>1873 \mathrm{~K}\left(1600^{\circ} \mathrm{C}\right)$, 36 hours at $1823 \mathrm{~K}\left(1550{ }^{\circ} \mathrm{C}\right)$, and 48 hours at $1773 \mathrm{~K}$ $\left(1500{ }^{\circ} \mathrm{C}\right)$. These equilibrium times had actually been determined in pre-experiments (different reaction times are used). To keep the reply short, the data are not presented here. However, the authors can provide the data on request.

(3) Prof. Jacob's third argument is the carbon deposition.

In the experiments, the flow rate of $\mathrm{Ar}$ is five times of that of $\mathrm{CO}+\mathrm{CO}_{2}$ or $\mathrm{H}_{2}+\mathrm{CO}_{2}$. To a certain extent, this can decrease the carbon deposition. After each experiment, the whole system including the quench chamber was checked. No carbon deposition was found.

(4) The fourth question raised by Prof. Jacob is that several oxide phases form in the composition range between $\mathrm{NbO}_{2}$ and $\mathrm{Nb}_{2} \mathrm{O}_{5}$.

In our experiments, the solid powder that had equilibrated with liquid copper in the lowest and highest oxygen partial pressures at all experimental temperatures was identified by XRD. The XRD patterns are shown in Figure 1. It can be seen clearly that all patterns can be indexed as $\mathrm{NbO}_{2}$.

Table II. The Activity Coefficient of $\mathrm{Nb}$ in $\mathrm{Cu}-\mathrm{Nb}$ Melts Containing Dilute Nb Obtained in the Present Study and That Calculated Using the Literature Data

The Activity Coefficient of $\mathrm{Nb}$ in $\mathrm{Cu}-\mathrm{Nb}$ Melts Containing Dilute $\mathrm{Nb}$ (Pure Liquid $\mathrm{Nb}$ as the Standard State)

Temperature $\left[\mathrm{K}\left({ }^{\circ} \mathrm{C}\right)\right]$ Hämäläinen Kaufman Present Study

\begin{tabular}{lrrr}
\hline $1773(1500)$ & 17.61 & 12.40 & 389.02 \\
$1823(1550)$ & 14.64 & 10.08 & 339.61 \\
$1873(1600)$ & 12.29 & 8.29 & 309.74 \\
$1898(1625)$ & 11.30 & 7.54 & 291.35 \\
\hline
\end{tabular}

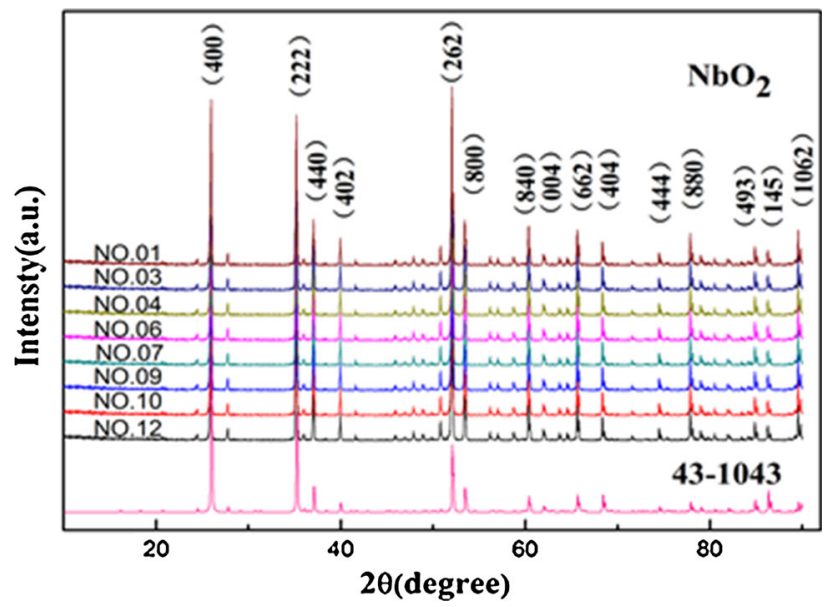

Fig. 1-The XRD patterns of $\mathrm{NbO}_{2}$ after equilibrium. 